\title{
Supernatural punishment beliefs as cognitively compelling tools of social control
}

\author{
Léo Fitouchi ${ }^{1 *} \&$ Manvir Singh* \\ ${ }^{1}$ Institut Jean Nicod, Départment d'études cognitives, ENS, Paris, France \\ ${ }^{2}$ Institute for Advanced Study in Toulouse, Toulouse, France \\ *Corresponding authors: leo.fitouchi@ens.fr, manvir.singh@iast.fr
}

\begin{abstract}
Why do humans develop beliefs in supernatural entities that punish uncooperative behaviors? Leading hypotheses maintain that these beliefs are widespread because they facilitate cooperation, allowing their groups to outcompete others in inter-group competition. Focusing on within-group interactions, we present a model in which people strategically endorse supernatural punishment beliefs to manipulate others into cooperating. Others accept these beliefs, meanwhile, because they are made compelling by various cognitive biases: They appear to provide information about why misfortune occurs; they appeal to intuitions about immanent justice; they contain threatening information; and they allow believers to signal their trustworthiness. Explaining supernatural beliefs requires considering both motivations to invest in their endorsement and the reasons others adopt them.
\end{abstract}

Keywords: cooperation, evolution, immanent justice, misfortune, morality, religion, social control

In many societies, supernatural agents are believed to reward cooperative behavior and to punish antisocial actions, such as murder, theft, adultery, or failure to share [1-4**]. We hereafter refer to such beliefs as (prosocial) supernatural punishment beliefs.

Why are these beliefs so widespread? According to a leading hypothesis, prosocial supernatural punishment beliefs motivate people to cooperate [5,6], allowing their groups to outcompete others, thereby fueling their spread in human populations [6]. This account relies on the premise that religious beliefs promote cooperation enough to substantially influence evolutionary dynamics - a sometimes contested empirical claim $\left[7^{*}-12\right]$.

Here, we focus on how within-group, strategic interactions can produce and sustain beliefs in moralistic supernatural entities. In particular, we argue that a key factor in the development of these beliefs is that people subjectively perceive them to be convenient tools for controlling others' cooperation in self-serving ways. We begin by reviewing evidence that, contrary to a common assumption $[1,13]$, beliefs in supernatural punishment are not limited to large-scale, complex societies. We then propose that they serve as cultural tools for social control, designed and selectively retained because people perceive them to be useful for incentivizing others' cooperation. We finally outline how various psychological biases make these beliefs compelling enough to be accepted and transmitted.

\section{Supernatural punishment beliefs are more widespread than we think}


Beliefs in the supernatural punishment of free-riding are central to the world religions that emerged in large, wealthy societies since the first millennium B.C., such as Christianity, Islam, and "karmic" religions $[1,3]$. Until recently, cognitive and evolutionary research has often considered these beliefs to be peculiarities of large-scale, politically stratified, and economically developed societies [1,6,14].

Recent studies, however, suggest that beliefs in moralizing supernatural agents are more widespread. Surveying ethnographies, Boehm found evidence of beliefs in supernatural punishment of antisocial behaviors in at least 12 of 18 forager societies [2]. Watts et al. found indications of such beliefs in the ethnographies of 37 of 96 Austronesian societies [15]. A recent study of 2,229 respondents in 15 field sites (e.g., Hadza of Tanzania, Tyva Republic, Fiji) showed that people are more likely than not to answer that their deity is concerned with punishing behaviors such as murder, theft, or deceit [16*]. Among the Ik of Uganda, 76.67\% of 60 participants answered that Earth spirits cause trouble to people who do not share with others [17]. A recent study of the Mentawai horticulturalists (Indonesia) found a widespread belief that a water spirit Sikameinan attacks people who fail to share meat within their clan $\left[4^{* *}\right]$. Sikameinan brings illness and misfortune to wrongdoers, who then need the help of a shaman and healing ceremonies to remove the spirit from their house and recover. As opposed to the "big gods" of world religions, the supernatural enforcers identified in these studies are neither all-knowing nor all-powerful, and their moral jurisdiction is typically restricted to a subset of social behaviors, such as meat-sharing or murder $\left[2,4^{* *}\right]$.

\section{The producer side: Supernatural punishment beliefs as tools of social control}

Where do prosocial supernatural punishment beliefs come from? Building on research stressing how individuals' motivations shape cultural traits [18-23], we argue that a key factor in the evolution of prosocial supernatural beliefs is the production and promotion of supernatural narratives that appear effective for motivating others' cooperation. For example, by promoting beliefs that "failure to share brings deadly illness", or that "adultery is punished by God", people may (not necessarily consciously) attempt to deter others' selfishness (Figure 1). Table 1 outlines testable predictions of this model.

\subsection{People try to induce others to cooperate}

Humans benefit from others' cooperation. As a result, they exhibit motivations to control others' selfishness by monitoring and punishing deviance, provided that such social control is sufficiently low-cost [24,25]. Examples of such social control include ostracism, condemnation, and coordinated physical punishment [24-26].

People also craft, tweak, and cumulatively refine cultural tools aimed at inspiring cooperative behavior in others. They teach and preach moral principles [27]. They narrate moral tales outlining bad behaviors and their dangerous consequences [28]. They design and experiment with rules aimed at controlling free-riding, limiting interpersonal conflicts, and preventing collective action problems, retaining the most effective-seeming [20,29]. We propose that supernatural punishment beliefs are one of many such cultural tools humans develop for everyday social control. 


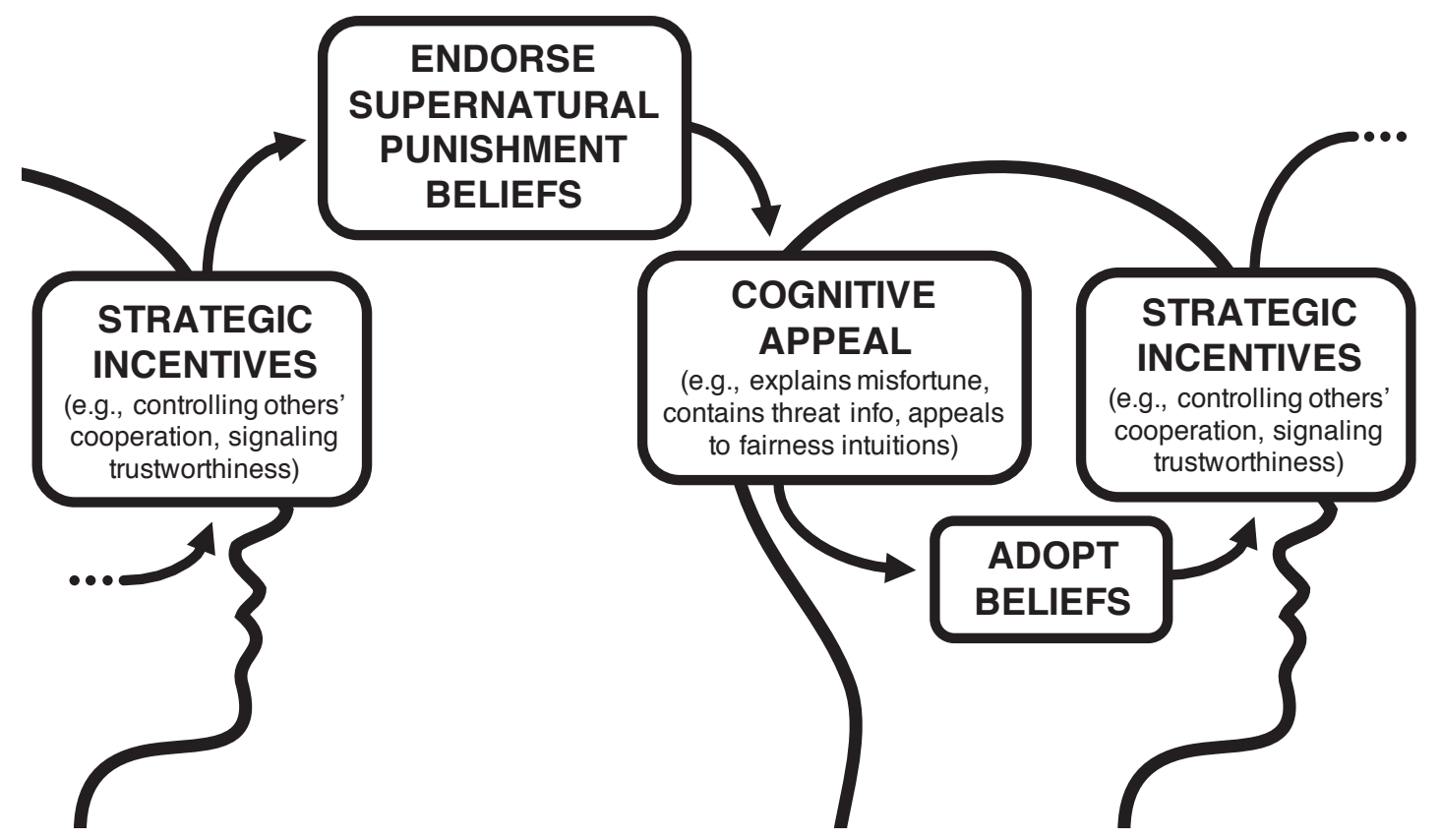

Figure 1. Strategic incentives and cognitive biases stabilize supernatural punishment beliefs in a population (here schematized as two individuals). Producers have strategic motivations to endorse supernatural punishment beliefs. Recipients accept the beliefs because of their cognitive appeal and are themselves motivated by strategic incentives to further endorse them.

\subsection{People use supernatural beliefs to influence others' behavior}

People use supernatural narratives to influence others' behavior-including behaviors unrelated to prosociality. Ethnographers have documented many cases of shamans exploiting their privileged access to the supernatural to manipulate others. Inuit shamans used their supernatural authority to demand sexual favors from their clients [30]. Some Shuar shamans leveraged their apparent powers to escape paying bride-price or engaging in bride-service [31]. Scholars have also noted how rulers of ancient chiefdoms and states crafted supernatural beliefs designed to consolidate they own power, such as by presenting themselves as the depositories of powerful gods' authority [3]. In many societies, taboos appear well designed to benefit men, elders, and other powerful individuals [20]. For example, menstrual taboos among the Dogon (Mali) have been shown to function as tools for men to ensure female sexual fidelity [32]. Given how readily people use supernatural beliefs to influence others, it is reasonable that they would also use them to induce people to be more cooperative.

\subsection{People believe that supernatural punishment beliefs make people more prosocial}

Our account assumes that people expect individuals who hold supernatural punishment beliefs to be more cooperative, a premise that is well-supported. Across 13 religiously diverse countries, participants judge that religious people are less likely than atheists to commit immoral acts (e.g., murder) [34]. Survey data indicate that, across 34 countries on 6 continents, a median of $45 \%$ of people consider the belief in god as necessary to "be moral and have good values" [35]. Ethnographic observations are consistent with these results. Among the Yaghan hunter-gatherers (Tierra del Fuego), informants admitted to using supernatural punishment beliefs to scare young people not to be lazy free-riders and to live as "good, 
industrious human beings" [36], while Mentawai respondents sometimes spontaneously suggested that belief in the water spirit Sikameinan causes people to share meat [ $4^{* *}$. Thus, despite ongoing debate over whether supernatural punishment beliefs actually motivate cooperation $\left[5,7^{*}-12,33\right]$, converging lines of evidence demonstrate that people believe that beliefs in moralizing gods make others more cooperative.

\subsection{Prosocial supernatural beliefs covary with social control motivations}

If prosocial supernatural beliefs serve as tools of social control, people should invest in them more when they are more motivated to control each other's behavior. Empirical work supports this prediction. Participants who experience a breach in trust or are otherwise motivated to punish norm violators are more likely than controls to endorse punitive religious belief $\left[37^{* * *}\right.$, $\left.38^{* *}, 39\right]$. At the populational level, "tighter" societies, characterized by a lower tolerance of deviance and more restrictive norms, are more likely to exhibit beliefs in punitive, moralizing gods [37**,40]. Beliefs in god and heaven and hell are, across countries, associated with lower trust in others $\left[7^{*}, 9\right]$ and with stronger tendencies to condemn uncooperative behaviors and sexual promiscuity $\left[7^{*}, 41,42\right]$. In sum, individuals endorse supernatural punishment beliefs when they perceive that other people need to be monitored to behave cooperatively. Table 1 lists other predictions for how supernatural punishments should vary across individuals and populations.

Table 1. Predictions

1. People should use beliefs in supernatural punishment to control each other's cooperation. We thus expect:

1.1. That individuals who desire higher levels of social control are more likely to promote supernatural punishment beliefs.

1.2. That societies with higher levels of social control, stricter social norms, and greater disapproval of deviance (i.e., greater "cultural tightness" [38]) are more likely to exhibit supernatural punishment beliefs.

1.3. That lower trust in others is associated with greater promotion of supernatural punishment beliefs.

1.4. That supernatural punishment beliefs will target those behaviors people are motivated to control.

2. People should invest in supernatural punishment beliefs when they perceive an added value over non-supernatural means of social control. We thus expect:

2.1. That people invest more in supernatural punishment beliefs when their desired level of social control is harder to achieve by non-supernatural means.

2.2. That supernatural punishment beliefs should preferentially target behaviors that are difficult to control by non-supernatural means.

3. People should invest in supernatural punishment beliefs as long as they believe that others will accept them.

4. Supernatural punishment belief should be endorsed as long as people believe them likely to motivate others' cooperation, regardless of their objective effectiveness in doing so. 


\section{The recipient side: reasons to adopt and endorse prosocial religious beliefs}

There is increasing evidence that humans have evolved cognitive mechanisms of "epistemic vigilance", allowing them to evaluate the reliability of communicated information (e.g., by checking its consistency with prior beliefs) to avoid being manipulated [43*]. Thus, if prosocial religious beliefs emerge as people attempt to manipulate others into cooperating, these beliefs must bypass espitemic vigilance. Below, we outline how cognitive biases and strategic incentives predispose people to accept prosocial supernatural beliefs (Figure 1).

\subsection{Supernatural punishment beliefs offer plausible explanations for misfortune}

Explaining and dealing with misfortune is a breeding ground for supernatural beliefs $[4,44-$ 46]. When facing harmful, fitness-consequential life events, such as illness, death or crop failure, people are motivated to search for plausible explanations that might allow them to control those events in the future. Many cognitive biases, such as the over-perception of intentional agents in nature [47] and mentalizing abilities allowing representing minds without bodies [48], predispose people to believe that misfortune is caused by supernatural agents [44]. Yet explanations of misfortune can also recruit moral intuitions, providing a lever for promoting prosocial supernatural beliefs. Psychological research has documented "immanent justice intuitions", or the widespread tendency to interpret misfortune as a retribution for past selfish behavior and good fortune as a reward for prosocial behavior [4951]. Researchers argue that these intuitions emerge as by-products of evolved justice intuitions $[1,50]$, according to which cooperative behaviors make people deserve benefits and uncooperative behaviors deserve to be punished by bad outcomes [52].

Misfortune-centered supernatural ecologies thus serve as potent opportunities for the promotion of supernatural punishment beliefs. When a misfortune happens, people consider different explanations (e.g., having offended a spirit, being attacked by magic) [4**]. Some individuals can then exploit immanent justice intuitions by promoting moralistic explanations, casting misfortune as supernatural punishment for previous failures to cooperate.

\subsection{Biases favoring threatening information}

Another reason supernatural punishment beliefs may overcome epistemic vigilance mechanisms is that they contain threatening information. Researchers argue that threatening information can bypass epistemic vigilance because people are often better off accepting the information than testing its reliability at a potentially dramatic cost [53]. Consistent with this logic, psychological experiments show that, compared to non-threatening information, people are more likely to perceive threatening information as plausible [54], more willing to transmit it [55], and more likely to judge its senders as more competent [56].

\subsection{Signaling trustworthiness}

People are further motivated to adopt beliefs because of reputational benefits that come from believing in them. Religious people are trusted more [34]. As a result, individuals who seek cooperative partners benefit from looking like sincere believers [57]. In line with this logic, research suggests not only that atheists often hide their lack of belief [58] but also that people who engage more in reputation-management are more likely to claim to be religious, especially in environments where religiosity is important [59]. 


\section{Conclusions}

Unlike previous accounts [6,13], our model is agnostic to whether supernatural punishment beliefs cause people to behave cooperatively. Many cultural traits, from shamanism [45] to rain magic [60] to divination [61], remain stable as long as people see them-potentially wrongly — as useful for achieving their goals [19]. Prosocial supernatural beliefs, we argue, are no different. People endorse them to motivate others to be cooperative. Their interaction partners accept these beliefs, meanwhile, because they are cognitively compelling and socially useful. Supernatural punishment beliefs, like so many cultural products, are shaped by people's psychological biases and strategic goals.

Acknowledgments: We thank Jean-Baptiste André, Nicolas Baumard, Theiss Bendixen, Benjamin Grant Purzycki, Aiyana Willard, and Camille Williams for their helpful feedback on previous versions of this manuscript. L.F. acknowledges funding by the EUR FrontCog grant ANR-17-EURE-0017. M.S. acknowledges IAST funding from the French National Research Agency (ANR) under the Investments for the Future (Investissements d'Avenir) program, grant ANR-17-EURE-0010. 


\section{References}

Papers of particular interest, published within the period of review, have been highlighted as:

* of special interest

** of outstanding interest

[1] N. Baumard, P. Boyer, Explaining moral religions, Trends in Cognitive Sciences 17 (2013) 272-280. https://doi.org/10.1016/j.tics.2013.04.003.

[2] C. Boehm, A biocultural evolutionary exploration of supernatural sanctionning, in: Evolution of Religion: Studies, Theories, and Critiques, 2008: pp. 143-152.

[3] R. Wright, The Evolution of God, New York: Little, Brown and Co, 2009.

[4] M. Singh, T.J. Kaptchuk, J. Henrich, Small gods, rituals, and cooperation: The Mentawai water spirit Sikameinan, Evolution and Human Behavior. 42 (2021) 61-72. https://doi.org/10.1016/j.evolhumbehav.2020.07.008.

** Shows that a Mentawai (Indonesia) water spirit is believed to punish people who fail to share meat and that people who suspect they have been attacked by the spirit pay shamans to conduct healing rituals in which prestigious individuals apologize to the spirit for the patient's stinginess

[5] M. Lang, B.G. Purzycki, C.L. Apicella, Q.D. Atkinson, A. Bolyanatz, E. Cohen, C. Handley, E. Kundtová Klocová, C. Lesorogol, S. Mathew, et al., Moralizing gods, impartiality and religious parochialism across 15 societies, Proc. R. Soc. B. 286 (2019) 20190202. https://doi.org/10.1098/rspb.2019.0202.

[6] A. Norenzayan, A.F. Shariff, W.M. Gervais, A.K. Willard, R.A. McNamara, E. Slingerland, J. Henrich, The cultural evolution of prosocial religions, Behavioral and Brain Sciences. 39 (2016). https://doi.org/10.1017/S0140525X14001356.

[7] P.O. Jacquet, F. Pazhoohi, C. Findling, H. Mell, C. Chevallier, N. Baumard, Predictive modeling of religiosity, prosociality, and moralizing in 295,000 individuals from European and non-European populations, Humanit Soc Sci Commun. 8 (2021) 9. https://doi.org/10.1057/s41599-020-00691-9.

* Analyzing data on more than 295,000 individuals in 108 countries (World Value Survey, European Value Study), finds a positive association between religiosity and social mistrust, and a negative association between religiosity and markers of investment in large-scale cooperation

[8] E. Ge, Y. Chen, J. Wu, R. Mace, Large-scale cooperation driven by reputation, not fear of divine punishment, R. Soc. Open Sci. 6 (2019) 190991.

https://doi.org/10.1098/rsos.190991. 
[9] L.W. Galen, C.A. Kurby, E.H. Fles, Religiosity, shared identity, trust, and punishment of norm violations: No evidence of generalized prosociality, Psychology of Religion and Spirituality. (2020) No Pagination Specified-No Pagination Specified. https://doi.org/10.1037/rel0000320.

[10] L. Oviedo, Religious attitudes and prosocial behavior: A systematic review of published research, Religion, Brain \& Behavior. 6 (2016) 169-184.

[11] C.M. Gomes, M.E. McCullough, The effects of implicit religious primes on dictator game allocations: A preregistered replication experiment., Journal of Experimental Psychology: General. 144 (2015) e94-e104. https://doi.org/10.1037/xge0000027.

[12] J. Billingsley, C.M. Gomes, M.E. McCullough, Implicit and explicit influences of religious cognition on Dictator Game transfers, Royal Society Open Science. 5 (2018) 170238. https://doi.org/10.1098/rsos.170238.

[13] A. Norenzayan, Big gods: How religion transformed cooperation and conflict, Princeton University Press, 2013.

[14] H.C. Peoples, P. Duda, F.W. Marlowe, Hunter-gatherers and the origins of religion, Hum Nat. 27 (2016) 261-282. https://doi.org/10.1007/s12110-016-9260-0.

[15] J. Watts, S.J. Greenhill, Q.D. Atkinson, T.E. Currie, J. Bulbulia, R.D. Gray, Broad supernatural punishment but not moralizing high gods precede the evolution of political complexity in Austronesia, Proceedings of the Royal Society B: Biological Sciences. 282 (2015) 20142556-20142556. https://doi.org/10.1098/rspb.2014.2556.

[16] B. Purzycki, A. Willard, E. Kundtová Klocová, C. Apicella, Q. Atkinson, A. Bolyanatz, E. Cohen, C. Handley, J. Henrich, M. Lang, C. Lesorogol, S. Mathew, R. McNamara, C. Moya, A. Norenzayan, C. Placek, M. Soler, J. Weigel, D. Xygalatas, C. Ross, The Moralization Bias of Gods' Minds: A Cross-Cultural Test, 2020.

* Based on questionnaires administrated to 2,229 individuals in 15 different field sites (e.g. Hadza, Mauritius, Turkana, Yasawa, Tyva Republic), shows that people often attribute at least some moral concern to "local deities" (e.g., ancestor spirits), even after controlling for the influence of "moralistic" deities

[17] C. Townsend, A. Aktipis, D. Balliet, L. Cronk, Generosity among the Ik of Uganda, Evolutionary Human Sciences. 2 (2020). https://doi.org/10.1017/ehs.2020.22.

[18] J.-B. André, N. Baumard, P. Boyer, The Mystery of Symbolic Culture: What fitness costs? What fitness benefits?, Open Science Framework, 2020.

https://doi.org/10.31219/osf.io/kdh7t.

[19] M. Singh, Subjective selection and the evolution of complex culture, PsyArXiv, 2020. https://doi.org/10.31234/osf.io/4t2ud. 
[20] M. Singh, R. Wrangham, L. Glowacki, Self-Interest and the Design of Rules, Hum Nat. 28 (2017) 457-480. https://doi.org/10.1007/s12110-017-9298-7.

[21] J.W. Moon, Why are world religions so concerned with sexual behavior?, Current Opinion in Psychology. 40 (2021) 15-19. https://doi.org/10.1016/j.copsyc.2020.07.030.

[22] L. Fitouchi, J.-B. André, N. Baumard, The intertwined cultural evolution of ascetic spiritualities and puritanical religions as technologies of self-discipline, Religion, Brain \& Behavior. (2021) 1-9. https://doi.org/10.1080/2153599X.2021.1881607.

[23] P. Boyer, Why Divination?: Evolved Psychology and Strategic Interaction in the Production of Truth, Current Anthropology. (2020) 000-000. https://doi.org/10.1086/706879.

[24] F. Guala, Reciprocity: Weak or strong? What punishment experiments do (and do not) demonstrate, Behavioral and Brain Sciences. 35 (2012) 1-15. https://doi.org/10.1017/S0140525X11000069.

[25] C. Boehm, Moral origins: the evolution of virtue, altruism, and shame, Basic Books, New York, 2012.

[26] L. Molleman, F. Kölle, C. Starmer, S. Gächter, People prefer coordinated punishment in cooperative interactions, Nat Hum Behav. 3 (2019) 1145-1153. https://doi.org/10.1038/s41562-019-0707-2.

[27] Briggs JL: 'Why don't you kill your baby brother?' the dynamics of peace in Canadian Inuit camps. In The anthropology of peace and nonviolence. Edited by Sponsel LL, Gregor T, Boulder: Lynne Rienner; 1994:115-181.

[28] B.M. Du Toit, Gadsup culture hero tales, The Journal of American Folklore. 77 (1964) 315-330.

[29] S. Gavrilets, M. Duwal Shrestha, Evolving institutions for collective action by selective imitation and self-interested design, Evolution and Human Behavior. 42 (2021) 1-11. https://doi.org/10.1016/j.evolhumbehav.2020.05.007.

[30] B.S. d'Anglure, J. Philibert, The shaman's share, or Inuit sexual communism in the Canadian central Arctic, Anthropologica. (1993) 59-103.

[31] M. Harner, The Jivaro: people of the sacred waterfalls. Berkeley, Univ. of California Press, 1972.

[32] B.I. Strassmann, N.T. Kurapati, B.F. Hug, E.E. Burke, B.W. Gillespie, T.M. Karafet, M.F. Hammer, Religion as a means to assure paternity, Proceedings of the National Academy of Sciences. 109 (2012) 9781-9785. https://doi.org/10.1073/pnas.1110442109.

[33] M.N. Stagnaro, A.A. Arechar, D.G. Rand, Are those who believe in God really more 
prosocial?, Religion, Brain \& Behavior. 10 (2020) 444-458.

https://doi.org/10.1080/2153599X.2019.1695656.

[34] W.M. Gervais, D. Xygalatas, R.T. McKay, M. van Elk, E.E. Buchtel, M. Aveyard, S.R. Schiavone, I. Dar-Nimrod, A.M. Svedholm-Häkkinen, T. Riekki, et al., Global evidence of extreme intuitive moral prejudice against atheists, Nat Hum Behav. 1 (2017) 0151. https://doi.org/10.1038/s41562-017-0151.

[35] C. Tamir, A. Connaughton, A.M. Salazar, People's thoughts on whether belief in God is necessary to be moral vary by economic development, education and age, Pew Research center. (2020) 39.

[36] M. Gusinde, F. Schütze, The Yahgan: the life and thought of the water nomads of Cape Horn, Die Feuerland-Indianer [The Fuegian Indians]. II (1937). https://ehrafworldcultures.yale.edu/document?id=sh06-001 (accessed March 19, 2021).

[37] J.C. Jackson, N. Caluori, S. Abrams, E. Beckman, M. Gelfand, K. Gray, Tight cultures and vengeful gods: How culture shapes religious belief., Journal of Experimental Psychology: General. (2021).

** Across five studies, tests and finds support for the hypothesis that "cultural tightness" (i.e., support for restrictive social norms and low tolerance of deviance) catalyzes punitive religious belief

[38] B.G. Purzycki, M.N. Stagnaro, J. Sasaki, Breaches of trust change the content and structure of religious appeals, Journal for the Study of Religion, Nature and Culture. 14 (2020) 71-94.

** Provides experimental evidence that experiencing a breach of trust in others-by riskily investing in cooperation with them and receiving no reciprocation in return-increases the chances of claiming that greed angers God.

[39] N. Caluori, J.C. Jackson, K. Gray, M. Gelfand, Conflict Changes How People View God, Psychol Sci. 31 (2020) 280-292. https://doi.org/10.1177/0956797619895286.

[40] J.C. Jackson, M. Gelfand, C.R. Ember, A global analysis of cultural tightness in nonindustrial societies, Proceedings of the Royal Society B. 287 (2020) 20201036.

[41] Q.D. Atkinson, P. Bourrat, Beliefs about God, the afterlife and morality support the role of supernatural policing in human cooperation, Evolution and Human Behavior. 32 (2011) 41-49. https://doi.org/10.1016/j.evolhumbehav.2010.07.008.

[42] J. Weeden, R. Kurzban, What predicts religiosity? A multinational analysis of reproductive and cooperative morals, Evolution and Human Behavior. 34 (2013) 440-445. https://doi.org/10.1016/j.evolhumbehav.2013.08.006.

[43] H. Mercier, Not born yesterday: the science of who we trust and what we believe, 
2020. https://doi.org/10.1515/9780691198842 (accessed March 9, 2021).

* Provides an extensive synthesis of evolutionary arguments and psychological evidence for cognitive mechanisms of epistemic vigilance, by which humans evaluate the reliability of communicated information

[44] P. Boyer, Informal religious activity outside hegemonic religions: wild traditions and their relevance to evolutionary models, Religion, Brain \& Behavior. (2019) 1-14. https://doi.org/10.1080/2153599X.2019.1678518.

[45] M. Singh, The cultural evolution of shamanism, Behavioral and Brain Sciences. 41 (2018). https://doi.org/10.1017/S0140525X17001893.

[46] M. Singh, Magic, explanations, and evil: The origins and design of witches and sorcerers, Current Anthropology. 62 (2021) 2-29. https://doi.org/10.1086/713111.

[47] M. Andersen, Predictive coding in agency detection, Religion, Brain \& Behavior. 9 (2019) 65-84. https://doi.org/10.1080/2153599X.2017.1387170.

[48] P. Bloom, Religion is natural, Developmental Science. 10 (2007) 147-151. https://doi.org/10.1111/j.1467-7687.2007.00577.x.

[49] K. Banerjee, P. Bloom, You get what you give: children's karmic bargaining, Developmental Science. 20 (2017) e12442. https://doi.org/10.1111/desc.12442.

[50] N. Baumard, C. Chevallier, What goes around comes around: The evolutionary roots of the belief in immanent justice, Journal of Cognition and Culture. 12 (2012) 67-80.

[51] M. Callan, R. Sutton, A. Harvey, R. Dawtry, Immanent justice reasoning: Theory, research, and current directions., Advances in Experimental Social Psychology. 49 (2014) $105-161$.

[52] L. Fitouchi, J.-B. André, N. Baumard, Are there really so many moral emotions? Carving morality at its functional joints, Oxford Handbook for Evolution and the Emotions, edited by Al-Shawaf L, Shackelford, T. K. New York: Oxford University Press, (in press).

[53] P. Boyer, Minds make societies: How cognition explains the world humans create, Yale University Press, 2018.

[54] D.M.T. Fessler, A.C. Pisor, C.D. Navarrete, Negatively-Biased Credulity and the Cultural Evolution of Beliefs, PLoS ONE. 9 (2014) e95167. https://doi.org/10.1371/journal.pone.0095167.

[55] T. Blaine, P. Boyer, Origins of sinister rumors: A preference for threat-related material in the supply and demand of information, Evolution and Human Behavior. 39 (2017). https://doi.org/10.1016/j.evolhumbehav.2017.10.001. 
[56] P. Boyer, N. Parren, Threat-Related Information Suggests Competence: A Possible Factor in the Spread of Rumors, PloS One. 10 (2015) e0128421.

https://doi.org/10.1371/journal.pone.0128421.

[57] M. Singh, M. Hoffman, Commitment and impersonation: A reputation-based theory of principled behavior, PsyArXiv, 2021. https://doi.org/10.31234/osf.io/ua57r.

[58] W.M. Gervais, M.B. Najle, How Many Atheists Are There?, Social Psychological and Personality Science. 9 (2018) 3-10. https://doi.org/10.1177/1948550617707015.

[59] C. Sedikides, J.E. Gebauer, Religiosity as Self-Enhancement: A Meta-Analysis of the Relation Between Socially Desirable Responding and Religiosity, Pers Soc Psychol Rev. 14 (2010) 17-36. https://doi.org/10.1177/1088868309351002.

[60] K. Hong, Slingerland \& Henrich, Magic and empiricism in early Chinese rainmaking -- A cultural evolutionary analysis, Current Anthropology, (in press).

https://doi.org/10.31234/osf.io/rp46t.

[61] Z. Hong, J. Henrich, The cultural evolution of epistemic practices, Hum Nat. (2021). https://doi.org/10.1007/s12110-021-09408-6. 